\title{
Differential induction of proto-oncogene expression and cell death in ocular tissues following ultraviolet irradiation of the rat eye
}

Hannes Wickert, Kurt Zaar, Andreas Grauer, Markus John, Manfred Zimmermann, Frank Gillardon

Department of Electron Microscopy, Würzburg, Germany $\mathrm{H}$ Wickert

Department of Internal Medicine I, University of Heidelberg, Heidelberg, Germany A Grauer M John

Department of Anatomy and Cell Biology II, University of Heidelberg, Heidelberg, Germany K Zaar

II Institute of Physiology, University of Heidelberg, Heidelberg, Germany $\mathrm{H}$ Wickert

M Zimmermann

Max-Planck-Institute, Department of Experimental

Neurology, Köln, Germany

F Gillardon

Correspondence to: Dr H Wickert, Department of Electron Microscopy, Am Hubland, University of Würzburg, D-97074 Würzburg, Germany.

Accepted for publication 18 August 1998

\begin{abstract}
Backgroundlaims-Ultraviolet (UV) irradiation of mammalian cells in culture evokes the transcriptional activation of different proto-oncogenes, among them members of the fos/jun family which are known to play an important role in cell proliferation and differentiation. To investigate in vivo UV induced proto-oncogene expression of irradiated ocular cells, the expression of JunB, JunD, and Egr-1 was analysed in the cornea, lens, and retina. Furthermore, UV radiation is known to induce pleiotrophic events in irradiated cells which include growth arrest, inflammation, and even cell death. In order to determine the type of cell death-for example, apoptosis versus necrosis, sections of UV irradiated rat eyes were further examined for distinct ultrastructural morphology of cell death and DNA fragmentation.
\end{abstract}

Methods-Eyes of anaesthetised rats were exposed to $1.5 \mathrm{~J} / \mathrm{cm}^{2}$ of ultraviolet radiation (280-380 nm). Animals were perfused 6 and 16 hours after irradiation and tissue sections of enucleated bulbi were processed for light and electron microscopy. Results-Under control conditions, Jun B was constitutively expressed in numerous superficial cells but also in scattered basal cells of the corneal epithelium. After UV exposure JunB expression was massively upregulated in many cells of the basal cell layers of the corneal epithelium, although during the entire experiment, both the corneal stroma and endothelium were JunB negative. In contrast, Egr-1 was expressed exclusively in lens epithelium showing only a faint expression pattern under control conditions. However, Egr-1 expression increased after UV exposure, so that many Egr-1 positive cells of the lens epithelium could be found several hours after UV illumination. JunD was expressed in single cells of both the ganglion cell layer and the inner nuclear layer of the retina, a pattern of expression which did not change after UV exposure. Regarding the type of cell death, features of apoptosis were only occasionally present in scattered superficial cells of the corneal epithelium of control eyes. After UV exposure, however, morphological signs of apoptosis and TUNEL positive cells were visible both in the stroma and epithelium of the rat cornea. In contrast, UV irradiated lens epithelial cells exhibited features typical of necrosis. The corneal endothelium and the retina did not show any indications of morphological changes indicative of cell death after UV irradiation.

Conclusion-Each proto-oncogene encoded protein was found to be expressed in a tissue specific manner and UV irradiation differentially modulates the expression pattern of these transcriptional regulatory proteins. This temporospatial expression pattern of these proteins is accompanied by two morphologically distinct types of cell death in the cornea and lens after UV irradiation. (Br F Ophthalmol 1999;83:225-230)

In recent years it has become evident that excess ultraviolet radiation (UV) can lead to severe abnormalities within radiation exposed tissues. Beside promotion of solar elastosis with wrinkling and coarsening of mammalian skin surface and induction of melanoma skin cancer, UV radiation also damages ocular tissues. ${ }^{1-4}$ Normally, short wavelength UV radiation does not cause any abnormalities in irradiated tissues because atmospheric chemicals (for example, ozone) effectively absorb light below approximately $290 \mathrm{~nm}$. However, when eyes are exposed to solar radiation-for example, at high altitudes or in snow covered areas, the initial response is macroscopic visible inflammation such as photokeratitis or pinguecula. ${ }^{4}$ In addition, chronic exposure of eyes to UV is heavily implicated in the development of cataracts (for example, opacities of the lens) and can also cause phototoxic effects to the retina. ${ }^{1-3}$

Although the histopathological signs of ultraviolet damage have been known for many years, ${ }^{4}$ the response at the molecular level to UV radiation is still unclear. Oxidative DNA damage and damage to cell membranes are thought to play key roles in eliciting the UV response and specific UV responsive cis acting elements have been identified. ${ }^{5}$ UV irradiated mammalian cells rapidly respond with the induction of various genes, both in vitro and in vivo, among them members of the fos, jun, and egr-1 family of transcription factors. ${ }^{78}$ The expression of proteins represents a cellular stress response which transactivates specific target genes. ${ }^{9}$ In UV irradiated ocular tissues little is known about the temporospatial 


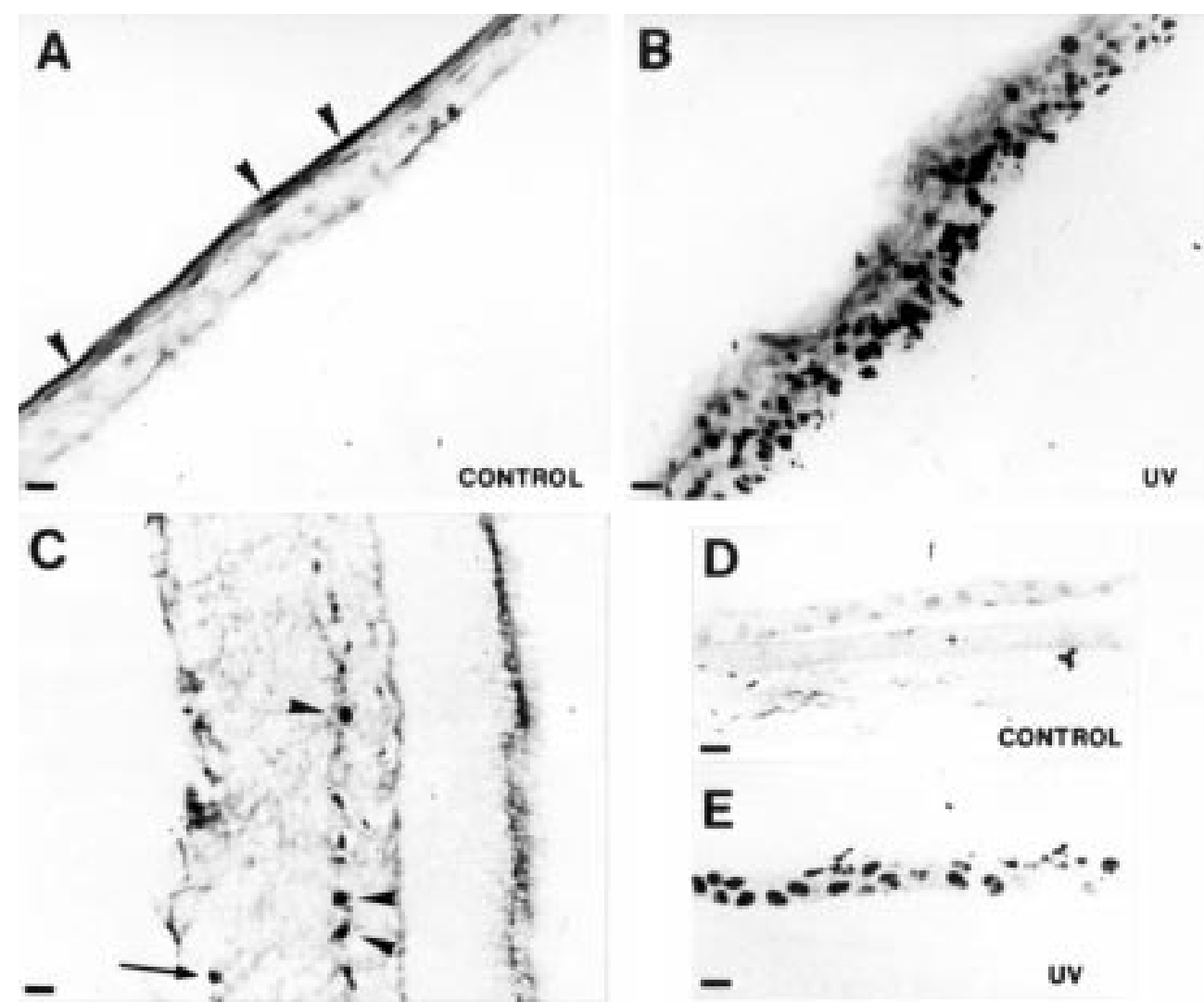

Figure 1 funB immunolocalisation in control $(A)$ and irradiated $(B)$ rat cornea. FunB exhibits a distinct basal expression in surface epithelial cells of control cornea (arrowheads in (A)) but is also present in scattered nuclei of the basal cell layers. However, after UV irradiation of the cornea funB is massively expressed in all basal cell layers (B). Note also the roughening of the irradiated eye surface (seen in (B)) compared with the surface of control eye $(A)$. In $(C) \mathcal{F u n D}$ immunolocalisation is shown in a longitudinal section of non-irradiated control retina. FunD exhibits a strong staining pattern in single cells of both the ganglion cell layer (arrow in $(C)$ ) and the inner nuclear layer of rat retina (arrowheads in (C)). Egr-1 immunolocalisation in control (D) and UV irradiated (E) lens epithelium. Egr-1 exhibits only a faint nuclear staining pattern in lens epithelial cells of control eyes, whereas UV irradiation of rat eyes evokes a selective upregulation of Egr-1 (E).

Figure 2 End labelling of fragmented nuclear DNA in longitudinal sections of control cornea (upper panel) and cornea 6 hours after UV irradiation (lower panel) using terminal transferase and fluorescein-dUTP. Note the absence of fluorescence signal in control cornea (arrowheads in upper panel) and the intense signal, which is visible mainly in the two uppermost layers of the corneal epithelium after $U V$ irradiation (lower panel). Arrowheads in the lower panel mark some TUNEL positive cells in the stroma of the UV irradiated rat cornea. expression pattern of these transcriptional regulatory proteins in vivo, and hitherto only c-Fos and c-Jun expression have been demonstrated in cornea, lens, and retina following UV irradiation. ${ }^{10}$

Apoptosis, sometimes described as programmed cell death, has been demonstrated to occur in retinal ganglion cells during experimental glaucoma, ${ }^{11}{ }^{12}$ after axotomy, ${ }^{12}$ and during ischaemic optic neuropathy. ${ }^{13}$ Apoptosis has also been observed in lens epithelial cells following calcimycin induced cataract formation. ${ }^{14}$ In these studies, however, little attention has been paid to the influence of ultraviolet irradiation on apoptosis in ocular tissues, although the eyes represent a heavily irradiated area on the human surface.

Given the apparent importance of UV irradiation induced damage to ocular tissue, and our lack of understanding of the molecular mechanisms involved in UV damage, we decided to investigate this phenomenon further. The temporospatial pattern of the stress response transcription factors JunB, JunD, and Egr-1 was characterised both before and after UV irradiation. The apparent differences in transcription factor expression was complemented with a characterisation of the types of cell death observed in UV irradiated tissue. 

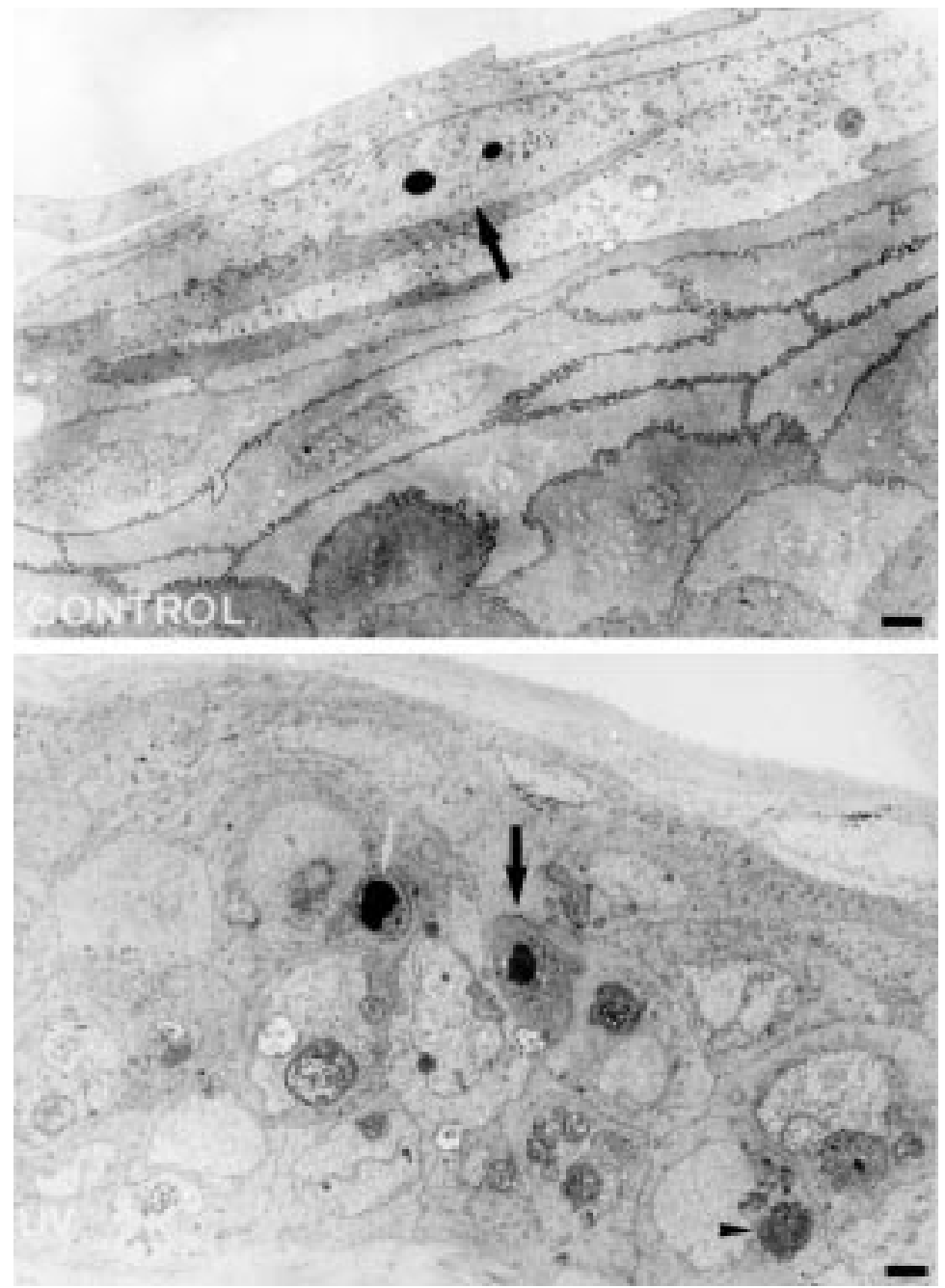

Figure 3 Electron microscopic appearances of apoptosis in control and UV irradiated rat eyes. Morphological signs such as segregation of compacted chromatin which is characteristic of apoptosis can be observed in single cells of the control epithelium (black arrow in upper panel). The lower panel illustrates pleiomorphic apoptotic changes in UV irradiated rat cornea, showing apoptotic bodies (white arrow) and phagocytosis of apoptotic cells by neighbouring epithelial cells (black arrow). The black arrowhead marks an already phagocytosed cell. Note also the loss of the uppermost surface cell layers (flat epithelial cells) after UV irradiation (lower panel) compared with normal eye surface (upper panel).

\section{Materials and methods}

The experiment was performed on male Sprague-Dawley rats (body weight 250-300 g), that were obtained from the Zentralanstalt für Versuchstierzucht (Hannover, Germany). Animals were kept under controlled conditions with 12 hours light-dark cycles, light on at 7 am. Four hours after the onset of the light period, the animals were anaesthetised (Nembutal, $60 \mathrm{mg} / \mathrm{kg}$, intraperitonally) and the right eye, which was clamped open, was exposed once to UV irradiation for 3 minutes. In contrast, the left eye was protected from the UV exposure by aluminium foil and served as a control. The UV radiation source consisted of a high pressure mercury arc lamp (Osram HBO 100W/2), two concave quartz lenses and a UV filter (Spindler and Hoyer UG 11). The eyes were irradiated with an intensity of 14 $\mathrm{mW} / \mathrm{cm}^{2}$ in the focus of the condensor system. ${ }^{10}$ Several measurements with a UV radiometer revealed that $65 \%$ of the energy was emitted within the UV-B wavelength range
(280-320 nm) while the other $35 \%$ remained within the UV-A range $(320-380 \mathrm{~nm})$.

After 6 and 16 hours, the rats were reanaesthetised ( $\mathrm{n}=3$ per time point) and transcardially perfused by $4 \%$ paraformaldehyde (in $100 \mathrm{mM}$ phosphate buffer). Eyes were removed, postfixed overnight, and cryoprotected in $30 \%$ sucrose (in phosphate buffered saline, PBS) for another 24 hours before cryostat sectioning $(20 \mu \mathrm{m})$. The sections were thaw mounted on gelatin covered slides and incubated for 48 hours at room temperature with primary antibodies (Jun B antibody: Santa Cruz SC46, diluted 1:500; Jun D antibody: Santa Cruz SC-74, diluted 1:500; and Egr-1 antibody: Santa Cruz SC 110, diluted 1:500). Antibody binding was then localised by standard avidin-biotin-peroxidase processing (Vector Lab, USA) using diaminobenzidine as chromogen.

For detection of DNA fragmentation in apoptotic nuclei, a recently reported protocol was modified and performed as follows. ${ }^{15}$ Frozen eyes were cut into $20 \mu \mathrm{m}$ cryostat sections and fixed in 4\% paraformaldehyde in PBS for 1 hour at room temperature. Sections were then washed in PBS and permeabilised by incubation in $0.1 \%$ Triton $\mathrm{X}-100$ in PBS for 2 minutes at $4^{\circ} \mathrm{C}$. Following several washing steps sections were covered with $10 \mu \mathrm{l}$ of $5 \times$ reaction buffer (Boehringer Mannheim), 0.3 nmol fluorescein-11-dUTP (Amersham), 3 nmol dATP, $2 \mu \mathrm{l} \mathrm{CoCl}_{2}$ (25 mM), 25 units of terminal transferase (Boehringer Mannheim) in a total volume of $50 \mu \mathrm{l}$, and incubated at $37^{\circ} \mathrm{C}$ for 1 hour in a humidified chamber. The reaction was terminated by several washes in TRIS-EDTA (50 mM, pH 8.0). Sections were mounted in glycerol/PBS (9:1) containing $2.5 \%$ 1,4-diazobicyclo-[2.2.2]-octan (Sigma) and viewed with a Olympus BX50F microscope under epifluorescence. Omission of terminal transferase or fluorescein-11-dUTP gave completely negative results (not shown).

To process ocular tissues for electron microscopy, a first fixation of the eye surface was achieved by dropping $2 \%$ glutaraldehyde in Pipes buffer ( $\mathrm{pH} 7.4$ ) directly onto the eye surfaces of deeply anaesthetised rats (pentobarbitone $60 \mathrm{mg} / \mathrm{kg}$ body weight, intraperitonally). Enucleated bulbi were postfixed for 2 hours in the same fixative. After cutting in the desired section planes, sections were washed in Pipes buffer, postfixed by the reduced osmium procedure of Karnovsky, ${ }^{16}$ dehydrated, and embedded in Epon 812. Ultrathin sections contrasted with uranyl acetate and alkaline lead citrate were examined using a transmission electron microscope (Phillips 301).

\section{Results}

After different survival times, reanaesthetised rats were perfused transcardially, the eyes were excised, and tissue sections were examined for transcription factor expression by light microscopy. The results obtained for each tissue type are described in the order they come into contact with UV light.

In the cornea JunB showed a intermediate expression in the uppermost cell layers of cor- 

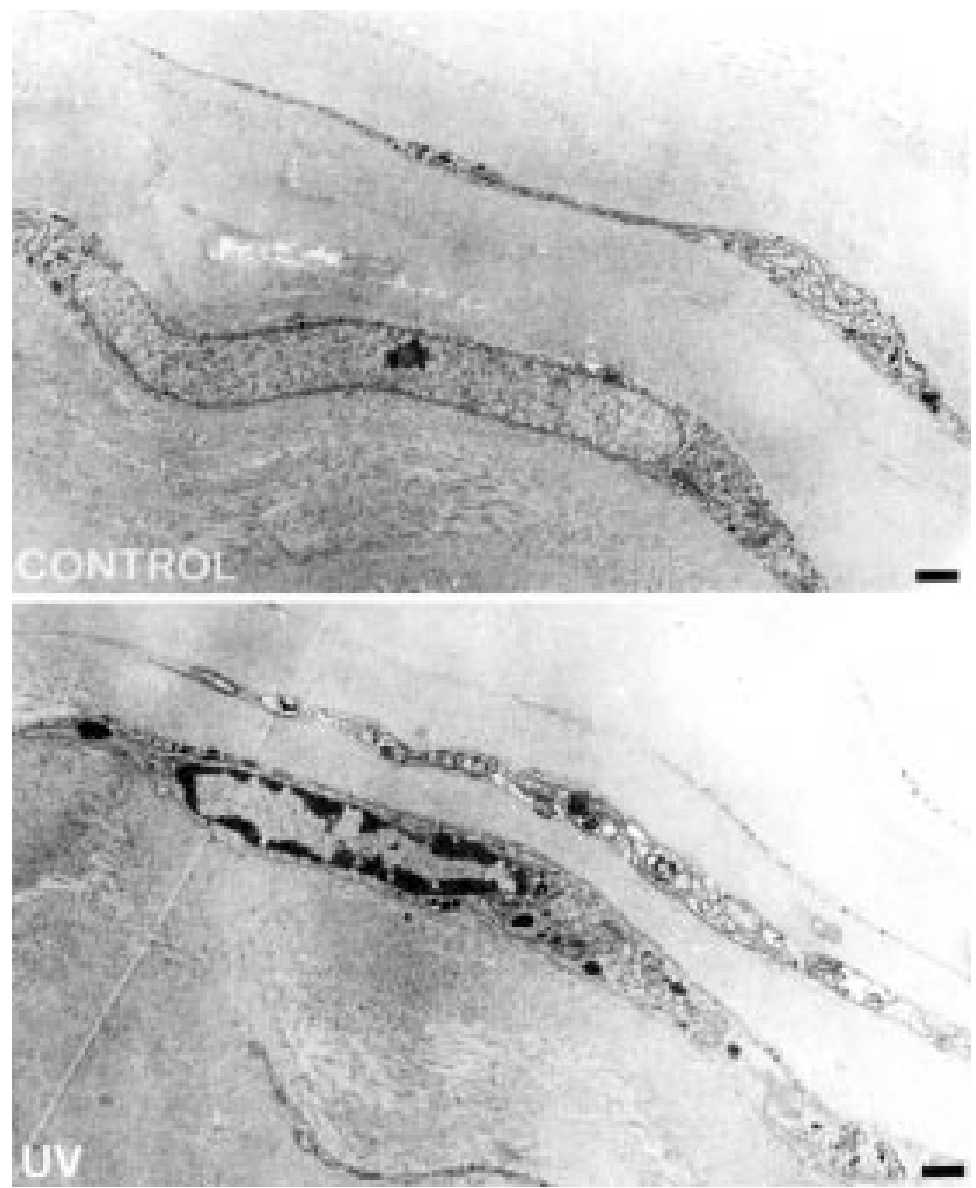

Figure 4 The upper panel shows a stromal cell of control rat cornea and the lower panel exhibits an apoptotic stromal cell following UV irradiation of the rat eye. Aggregation of the chromatin in large compact masses abuting on the nuclear membrane is clearly visible in the UV damaged stromal cell. Note also the well preserved cell organelles such as mitochondria.

neal epithelium of control eyes, but was also present in scattered basal cell layers of the untreated cornea (Fig 1A, Table 1). JunB immunoreactivity was not visible in the corneal endothelium, the lens epithelium, or the retina of rat eyes (Table 1). Intense labelling of many cell nuclei was observed throughout the basal cell layer of the corneal epithelium 6 hours after UV exposure (Fig 1B). Sixteen hours post-irradiation, expression of JunB in the basal cell layers of UV irradiated cornea had declined, but was still above control expression level. At the same time points, expression of JunB was not detected in UV irradiated lens epithelium and in retina.

Egr-1 expression in the lens of control eyes was restricted to the epithelium, where faint Egr-1 expression was visible in numerous cells (Fig 1D, Table 1). Six hours after UV exposure numerous nuclei with high intensity of Egr-1

Table 1 Expression of $\mathcal{F u n B , ~ F u n D , ~ a n d ~ E g r - 1 ~ p r o t e i n s ~ i n ~}$ ocular tissues of untreated rats and following UV irradiation

\begin{tabular}{|c|c|c|c|c|c|c|}
\hline & \multicolumn{3}{|l|}{ Basal } & \multicolumn{3}{|l|}{$U V$} \\
\hline & Cornea & Lens & Retina & Cornea & Lens & Retina \\
\hline Jun B & + & - & - & $\uparrow \uparrow$ & $\leftrightarrow$ & $\leftrightarrow$ \\
\hline Jun D & - & - & + & $\leftrightarrow$ & $\leftrightarrow$ & $\leftrightarrow$ \\
\hline Egr-1 & - & + & - & $\leftrightarrow$ & $\uparrow$ & $\leftrightarrow$ \\
\hline
\end{tabular}

+=basal expression; -=no expression; $\leftrightarrow=$ no change; $\uparrow=$ in crease; $\uparrow \uparrow=$ massive increase. labelling were detectable in the central zone of lens epithelium (Fig 1E, Table 1). At the end of our observation period, 16 hours following UV irradiation, the expression of Egr-1 in UV irradiated rat lens decreased, but was still above control level (data not shown).

Retina tissue shows a strong basal expression of JunD in some cells of the ganglion cell layer or in the inner nuclear layer of control retina (Fig 1C, Table 1). Cells of the cornea and lens of non-irradiated rat eyes, in contrast, displayed no detectable nuclear JunD immunostaining (Table 1). Furthermore, the expression pattern of JunD in retinal tissue did not change significantly after UV irradiation.

\section{DNA FRAGMENTATION IN RAT EYES AFTER UV EXPOSURE}

Apoptotic cell death is characterised by the fragmentation of the genomic DNA, a phenomenon readily observed using the TUNEL assay where DNA breaks are labelled with a fluorescent marker. Examination of sections prepared from the control samples indicated, as expected, no apoptotic cells were present (Fig 2, upper panel, arrowheads mark the corneal epithelium). However, 6 hours following UV irradiation, an intense labelling of DNA breaks was observed not only in numerous cells located in the uppermost layers of the corneal epithelium but also in scattered stromal cells (Fig 2, lower panel). Within the cornea, nuclear DNA damage was detectable up to 16 hours following irradiation. However, no significant fluorescence signal could be observed in the corneal endothelium, lens epithelium, or retina of UV irradiated rat eyes (data not shown).

DIFFERENT ULTRASTRUCTURAL MORPHOLOGY OF CELL DEATH IN RAT EYES IS OBSERVED

FOLLOWING UV EXPOSURE

Other than apoptotic cell death, cells also undergo necrosis, a more sudden death characterised by immediate cessation of cell functions. These death phenomena can be morphologically distiguished from one another; apoptotic cells are hereby characterised by a series of morphological characteristics including cytoplasmic shrinkage, chromatin condensation that abuts on the nuclear membrane, well preserved organelles, and generation of apoptotic bodies that are phagocytosed by neighbouring cells while necrotic cells exhibit swollen nuclei and chromatin that has clumped into ill defined aggregates. ${ }^{17}$ Since reports indicate that necrotic cells may erroneously give a TUNEL positive signal, ${ }^{18}$ we further examined cell death using electron microscopic examination.

Ultrathin sections revealed apoptotic features such as chromatin condensation in single cells of the uppermost layers of the control corneal epithelium (Fig 3, upper panel). Sixteen hours after UV exposure the corneal epithelium displayed pleiomorphic apoptotic changes including apoptotic bodies and their phagocytosis by neighbouring cells (Fig 3, lower panel). In the corneal stroma, however, characteristic features of apoptosis were only 


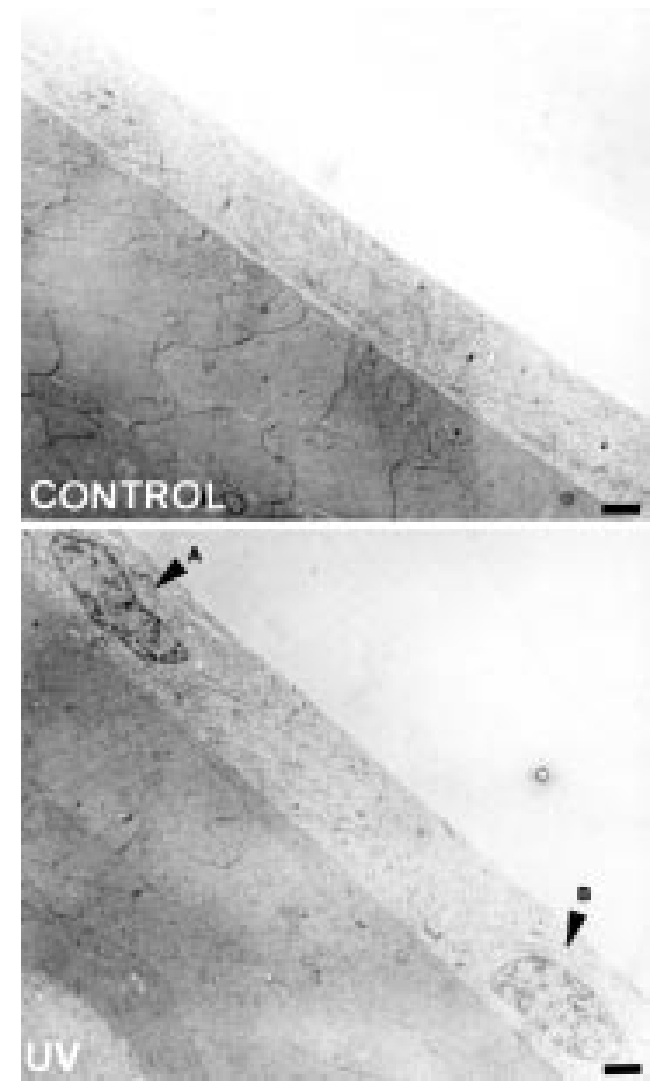

Figure 5 Lens epithelium of control rat eyes (upper panel) and after UV exposure (lower panel). Arrowheads in both panels indicate cell nuclei of necrotic lens epithelial cells $(A, B)$. After UV irradiation the cell nuclei exhibit the (A,B). After $U V$ irradiation the cell nuclei exhibit the
typical features of necrosis such as swollen nuclei and typical features of necrosis such as swollen nuclei and
chromatin that has clumped into ill defined, loosely textured aggregates. Cells $(A)$ is shown at higher magnification in Figure 6.

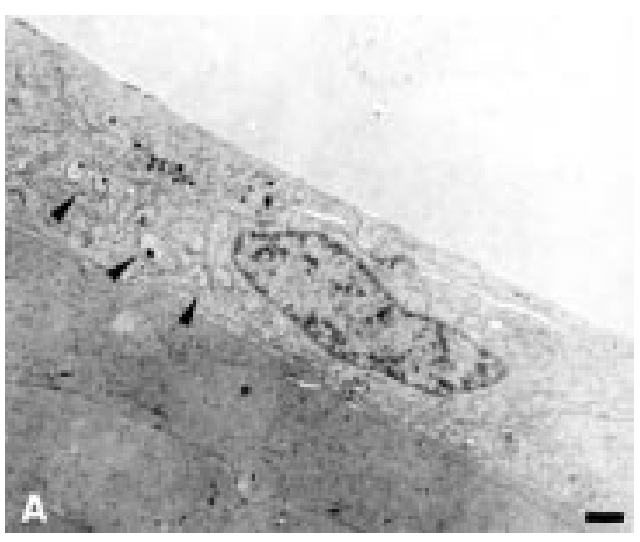

Figure 6 One of the necrotic lens epithelial cells in Figure 5 (indicated with $A$ ) at higher magnification. Note the swollen mitochondria and the appearance of flocculent densities in the matrix of the mitochondria (arrowheads).

present in single cells following UV irradiation of the rat eye, demonstrating compacted chromatin and well preserved cell organelles such as mitochondria (Fig 4). The corneal endothelium and the retina did not show any morphological signs of apoptosis or necrosis following UV irradiation over the whole observation period (data not shown).

In contrast with apoptotic features found in the UV irradiated cornea, cells of the lens epithelium exhibited the typical morphological appearances of necrosis which include ill defined edges of the compacted chromatin, the swelling of cell organelles, and the appearance of densities in the matrix of mitochondria (Figs 5 and 6$)$.

\section{Discussion}

The most prominent result of this work is the diversity of molecular responses to UV damage in ocular tissue. Not only does the temporospatial expression pattern of JunB, JunD, and Egr-1 vary, but also the final outcome of the UV induced cell death.

The basal expression of JunB in the nonirradiated corneal epithelium has been demonstrated to be principally restricted to the surface cell layers. JunB, from other work, has been proposed to have a role in growth arrest and differentiation ${ }^{19}$; an observation which makes its expression in the epithelia of the cornea reasonable, where cells which on arrival at the surface stop growing and differentiate, adopting a flat shape. The increase in JunB expression in the basal cell layers following UV irradiation may be a response to induce growth arrest, allowing these cells to repair the DNA lesions created by the UV radiation. Alternatively, the higher levels of JunB induced by UV irradiation may antagonise the pro-apoptotic action of c-Jun, as has been described in other systems. ${ }^{9}{ }^{20}$ Indeed, c-Jun and JunB show similar patterns of temporospatial expression in the corneal epithelium following UV irradiation. ${ }^{10}$ Several lines of evidence support this "protective" hypothesis of JunB in response to UV irradiation. Firstly, jun-B mRNA expression increases in UVC irradiated Chinese hamster ovary cells as a defence against DNA damage induced by UV radiation. ${ }^{21}$ Secondly, JunB is preferentially expressed in rat skin following chronic ultraviolet irradiation indicating that this protein may indeed have a protective function in irradiated cells. ${ }^{22}$ Given the proposition that JunB exerts a protective role, why do we then observe apoptosis? Several possibilities could account for this. (i) Not all cells in the corneal epithelium express JunB, we observe a punctate pattern of expression. (ii) An acute dose of UV irradiation could still induce apoptosis should JunB not sufficiently induce the protective response. (iii) There may still remain factors, other than JunB and c-Jun, which play a role in the induction of cell death in these tissues.

There was no apparent effect of UV deep within the eye. This observation results from the expression of JunD not altering after UV. However, since JunD may be more involved in supporting the basic cell metabolism of the retinal ganglion cell layer, ${ }^{23}$ other factors as yet uncharacterised, may be altered.

The physiological significance of Egr-1 upregulation in the central zone of the lens following UV irradiation is not known. Some idea may be obtained from a report indicating that mouse NIH 3T3 cells express higher levels of Egr-1 after UV irradiation, ${ }^{8}$ perhaps a common role for Egr-1 in the lens could be envisaged. Interestingly, when we correlate Egr-1 expression and the necrotic appearances of dead cells, it would be tempting to speculate what 
we may see is Egr-1 induced oncosis, a genetically controlled cell death exhibiting morphological features of necrosis. ${ }^{24}$

That the TUNEL assay fails to discriminate between apoptosis and random DNA fragmentation in necrotic/oncotic cells was borne out in this work. Using the above mentioned morphological criteria, we clearly showed apoptotic cell death in epithelial and stromal cells of rat cornea following UV irradiation. However, ultrastructural investigation of dead cells in the lens clearly indicate these cells were necrotic. An important aspect of the work reused here is - why the different cell deaths? Recent work indicates that lens epithelial cells appear more susceptible to radiation injury than corneal cells and, in fact, it has been shown that it is possible to damage the lens by UV irradiation without concomitantly inducing corneal damage. ${ }^{25}$ Furthermore, one possible mechanism of damage to the lens epithelium by UV exposure may involve damage to the epithelial cell plasma membrane ${ }^{126}$ and membrane breakdown is a typical feature of necrosis. ${ }^{17} \mathrm{In}$ addition, exposure to UV causes intracellular production of highly active oxygen species. ${ }^{67}$ Recent work suggests that the level of this oxidative stress determines whether a cell undergoes necrosis or apoptosis ${ }^{27}$ and oxidative stress has been demonstrated to cause massive necrotic cell death in lens organ culture within some hours. ${ }^{12}$ However, the induction of either apoptosis or necrosis may not only depend on the injurious stimulus but may also depend on the cell type and perhaps on its genetic constitution which produces the different types of death.

The authors thank Dr Paul Horrocks for critially reviewing the manuscript. This work was supported by a grant from Sandoz Stiftung für Medizinische Forschung Nürnberg, Germany.

1 Spector A, Wang GM, Wang RR, et al. A brief photochemically induced oxidative insult causes irreversible lens damage and cataract I. Transparency and epithelial cell layer. Exp Eye Res 1995; 60:471-81.

2 Spector A, Wang GM, Wang RR, et al. A brief photochemically induced oxidative insult causes irreversible lens damage and cataract II. Mechanism of action. Exp Eye Res 1995;60:483-93.

$3 \mathrm{Li}$ ZL, Tso MOM, Jampol LM, et al. Retinal injury induced by near ultraviolet radiation in aphakic and pseudophakic monkey eyes. Retina 1990;10:301-14.

4 Buschke W, Friedenwald JS, Moses SG. Effects of ultraviolet irradiation on corneal epithelium: mitosis, nuclear fragmentation, post-traumatic cell movements, loss nuclear fragmentation, post-traumatic cell movements,
of tissue cohesion. F Cell Comp Physiol 1945;26:147-64.

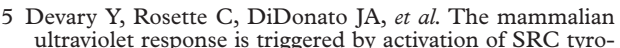
ultraviolet response is triggered by
sine kinases. Cell 1992;71:1081-91.

6 Janssen YMW, van Houten B, Borm PJA, et al. Biology of disease. Cell and tissue responses to oxidative damage. $L a b$ Invest 1993;3:261-74.

7 Tyrell RM. Activation of mammalian gene expression by the UV component of sunlight-from models to reality. BioEssays 1996;18:139-48.

8 Huang RP, Adamson ED. A biological role for Egr-1 in cell survival following ultraviolet irradiation. Oncogene 1995;10: 467-75.

9 Angel P, Karin M. The role of Jun, Fos and the AP-1 complex in cell proliferation and transformation. Biochim plex in cell proliferation and
Biophys Acta 1991;1072:129-57.

10 Gillardon F, Zimmermann M, Uhlmann E. Expression of c-Fos and c-Jun in the cornea, lens and retina after ultraviolet irradiation of the rat eye and effects of topical antisense oligodeoxynucleotides. Br F Ophthalmol 1995;79: 277-81.

11 Garcia-Valenzuela E, Shareef S, Walsh J, et al. Programmed cell death of retinal ganglion cells during experimental glaucoma. Exp Eye Res 1995;61:33-44.

12 Quigley HA, Nickells RW, Zack DJ, et al. Ganglion cell death in experimental monkey glaucoma and axotomy occurs by apoptosis. Invest Ophthalmol Vis Sci 1994;35: 2083-8.

13 Levin LA. Apoptosis of retinal ganglion cells in anterior ischemic optic neuropathy. Arch Ophthalmol 1996;114: $488-91$.

$14 \mathrm{Li}$ WC, Kuszak JR, Wang GM, et al. Calcimycin-induced lens epithelial cell apoptosis contributes to cataract formation. Exp Eye Res 1995;61:91-8.

15 Gavrieli Y, Sherman Y, Ben-Sasson SA. Identification of programmed cell death in situ via specific labeling of nuclear DNA fragmentation. If Cell Biol 1992;119:493501.

16 Karnovsky MJ. Use of ferricyanide-reduced osmium tetroxide in electron microscopy. F Cell Biol 1971;51:146a.

17 Kerr JFR, Harmon BV. Definition and incidence of apoptosis:an historical perspective. In: LD Tomei, FO Cope, eds. Apoptosis: the molecular basis of cell death. New

Charriaut-Marlangue C, Ben-Ari Y. A cautionary note on the use of the TUNEL stain to determine apoptosis. NeuroReport 1995;7:61-4.

19 Schlingensiepen $\mathrm{KH}$, Schlingensiepen R, Kunst M, et al. Opposite functions of jun-B and c-jun in growth regulation and neuronal differentiation. Dev Gen 1993;14:305-12.

20 Bossy-Wetzel E, Bakiri L, Yaniv M. Induction of apoptosis by the transcriptionfactor c-Jun. EMBO f 1997;7:1695709.

21 Dosch J, Kaina B. Induction of c-fos, c-jun, junB and junD mRNA and AP-1 by alkylating mutagens in cells deficient and proficient for the DNA repair protein o6methylguanine DNA methyltransferase (MGMT) and its relationship to cell death, mutation induction and chromosomal instability. Oncogene 1996;13:1927-35.

22 Gillardon F, Eschenfelder C, Uhlmann E, et al. Differential regulation of $\mathrm{c}$-fos, fos $\mathrm{B}, \mathrm{c}$-jun, jun $\mathrm{B}, \mathrm{bcl}-2$ and bax expression in rat skin following single or chronic ultraviolet irradiation and in vivo modulations by antisense oligodeirradiation and in vivo modulations by antisense oligod

23 Bravo R. Growth factor inducible genes in fibroblasts. In: A Habenicht, ed. Growth factors, differentiation factors and cytokines. Berlin: Springer, 1990:324-43.

24 Majno G, Joris I. Apoptosis, oncosis and necrosis. Am $\mathcal{F}$ Pathol 1995;146:3-15.

25 Jose JG. Posterior cataract induction by UV-B radiation in albino mice. Exp Eye Res 1986;42:11-20.

26 Hightower K, McCready J. Mechanisms involved in cataract development following near-ultraviolet radiation of cultured lenses. Curr Eye Res 1992;11:679-89.

27 Lennon SV, Martin SJ, Cotter TG. Dose-dependent induction of apoptosis in human tumor cell lines by widely diverging stimuli. Cell Prolif 1991;24:203-14. 